\title{
Evaluation, modification and validation of a set of asthma illustrations in children with chronic asthma in the emergency department
}

\author{
Joanie Tulloch BSP PharmD ${ }^{1,2}$, Régis Vaillancourt BPharm PharmD ${ }^{1}$, Danica Irwin BScPharm ${ }^{1}$, Elena Pascuet MSc ${ }^{1}$
}

\begin{abstract}
J Tulloch, R Vaillancourt, D Irwin, E Pascuet. Evaluation, modification and validation of a set of asthma illustrations in children with chronic asthma in the emergency department. Can Respir J 2012;19(1):26-31.
\end{abstract}

OBJECTIVES: To test, modify and validate a set of illustrations depicting different levels of asthma control and common asthma triggers in pediatric patients (and/or their parents) with chronic asthma who presented to the emergency department at the Children's Hospital of Eastern Ontario, Ottawa, Ontario.

METHODS: Semistructured interviews using guessability and translucency questionnaires tested the comprehensibility of 15 illustrations depicting different levels of asthma control and common asthma triggers in children 10 to 17 years of age, and parents of children one to nine years of age who presented to the emergency department. Illustrations with an overall guessability score $<80 \%$ and/or translucency median score $<6$, were reviewed by the study team and modified by the study's graphic designer. Modifications were made based on key concepts identified by study participants.

RESULTS: A total of 80 patients were interviewed. Seven of the original 15 illustrations (47\%) required modifications to obtain the prespecified guessability and translucency goals.

CONCLUSION: The authors successfully developed, modified and validated a set of 15 illustrations representing different levels of asthma control and common asthma triggers.

PRACTICE IMPLICATIONS: These illustrations will be incorporated into a child-friendly asthma action plan that enables the child to be involved in his or her asthma self-management care.

Key Words: Action plan; Asthma; Health literacy; Illustrations; Pediatrics; Self-management

$\Delta$ sthma affects an estimated $8.5 \%$ of Canadian children (1). It is A exceeded only by injuries and pneumonia as a cause for pediatric hospitalizations (2). In Canada, more than 146,000 emergency department (ED) visits each year are attributed to an asthma-related event, with an estimated $\$ 12$ billion spent annually on asthma alone (3). Given the significant prevalence and economic burden of this disease, there is increased interest in improving asthma treatment, specifically improving asthma self-management through enhanced patient education (4).

Written asthma action plans are recommended by national and international asthma guidelines (4). Despite conflicting evidence, written asthma action plans are believed to improve asthma outcomes and decrease health care use (5-8). Unfortunately, research indicates that fewer than $20 \%$ of asthmatic patients receive a written asthma action plan and, of those who do, the plan is often presented in text format that is difficult for pediatric patients and those with low-literacy skills to comprehend, and is written at a level above the fifth-grade reading standard recommended by health literacy experts $(5,8-12)$. Written asthma action plans presented in national asthma guidelines (the National Asthma Education and Prevention Program Expert [NAEPP] Guidelines, the Global Initiative for Asthma Guidelines and the American

\section{Lévaluation, la modification et la validation d'une série d'illustrations sur l'asthme chez des enfants ayant de l'asthme chronique au département d'urgence}

OBJECTIFS : Mettre à l'essai, modifier et valider une série d'illustrations démontrant divers niveaux de contrôle de l'asthme et des déclencheurs courants de l'asthme chez des patients pédiatriques (et leurs parents) atteints d'asthme chronique qui se présentaient au département d'urgence du Centre hospitalier pour enfants de l'est de l'Ontario, à Ottawa, en Ontario.

MÉTHODOLOGIE : Les auteurs ont recouru à des entrevues semistructurées faisant appel à des questionnaires de prévisibilité et de transparence pour vérifier la compréhensibilité de 15 illustrations démontrant divers niveaux de contrôle de l'asthme et des déclencheurs courants de l'asthme chez des enfants de dix à 17 ans et les parents d'enfants de un à neuf ans qui consultaient au département d'urgence. L'équipe de l'étude a revu les illustrations dont l'indice de prévisibilité global était inférieur à 80 $\%$ et dont l'indice médian de transparence était inférieur à six et les a fait modifier par le graphiste de l'étude. Les modifications étaient effectuées d'après les principaux concepts déterminés par les participants à l'étude.

RÉSULTATS : Au total, 80 patients ont passé une entrevue. Sept des 15 illustrations originales $(47 \%)$ ont dû être modifiées pour parvenir aux objectifs de prévisibilité et de transparence précisés à l'avance.

CONCLUSION : Les auteurs ont réussi à élaborer, à modifier et à valider une série de 15 illustrations représentant divers niveaux de contrôle de l'asthme et de déclencheurs courants de l'asthme.

CONSÉQUENCES POUR LA PRATIQUE : Ces illustrations seront intégrées à un plan d'action sur l'asthme adapté aux enfants qui permettent à l'enfant de participer à ses soins d'autogestion de l'asthme.

Academy of Allergy Asthma and Immunology 2000 pediatric guidelines) are written at a median eighth-grade reading level (range, seventh to ninth grade) (11).

Studies have recognized that health literacy is an instrumental factor in treatment adherence, and that inadequate health comprehension is commonly associated with worse health knowledge and poorer health outcomes (13-17). While data regarding children's perceived level of asthma control are scarce, and only a few studies have evaluated the extent to which inadequate health literacy serves as a barrier to optimal patient care, low parental literacy has been associated with worse asthma care in children (13). A retrospective review by DeWalt et al (13) found that asthmatic children of parents with low literacy skills were 1.4 times more likely to visit the ED, 4.6 times more likely be hospitalized for asthma and missed on average 2.8 more days of school than children of parents with higher levels of literacy.

Despite recommendations for developing low-literacy health information and specific advice from parents with limited health literacy to make education material more clear $(15,18)$, a recent systematic review on literacy and child health (15) reported that most child health information continues to be written at a level above the fifthgrade reading standard. Attention, therefore, must be devoted to

${ }^{1}$ Children's Hospital of Eastern Ontario, Department of Pharmacy, Ottawa; ${ }^{2}$ Doctor of Pharmacy Program, Faculty of Pharmaceutical Science,

The University of British Columbia, Vancouver, British Columbia

Correspondence: Mr Régis Vaillancourt, Pharmacy Department, Children's Hospital of Eastern Ontario, 401 Smyth Road, Ottawa,

Ontario K1H 8L1. Telephone 613-737-7600 ext 2231, e-mail rvaillancourt@cheo.on.ca 
reducing the complexity of child health information. While health literacy experts recommend that written health education material be written at or below the fifth-grade reading level (19), research indicates that easy-to-read instructions are more helpful to good readers than to poor readers (20). Therefore, easy-to-read health information is only part of the solution to helping people with low-literacy skills comprehend written health education material (19).

Another way to reduce the complexity of child health information is to incorporate pictorial aids into written health information $(21,22)$. Incorporating pictorial aids holds particular promise for helping individuals who have difficulty with reading and interpreting textual instructions $(12,19,23)$. While studies investigating the direct use of pictorial aids in pediatric patients are limited in both simulated and clinical settings $(1,24)$, pictorial aids have been shown to increase patient attention, comprehension, recall of counselling points and treatment adherence in adult patients with low-literacy skills $(12,19,23,25,26)$. Yin et al (26) demonstrated significantly reduced medication administration errors and improved treatment adherence in children with low-literacy caregivers through the incorporation of a pictogram-based intervention as part of routine medication counselling.

The success of using pictorial aids to enhance both written and oral health information depends on the comprehensiveness of the images developed. If an asthma action plan incorporating pictorial aids is going to be used to better guide children (and their parents) in the self-management of their asthma, it is important that both the pictorial aids and the action plan itself be designed and validated for use in the population in which it will serve. The health information provided must accommodate the lowest literacy level of the target population to equip all patients with the skills and autonomy needed to act appropriately in the self-management of their disease. In 2001, the International Pharmaceutical Federation adopted a statement regarding the pharmacists' responsibility and role in teaching children and adolescents about medication. The statement reads that pharmacists should provide "written material, which in their professional judgment, is appropriate for children and adolescents of the relevant age group, to supplement information given orally" (27).

As an initial step in the development of an age-appropriate pediatric asthma action plan, the objective of the present study was to evaluate, modify and validate a set of illustrations that depict different levels of asthma control, and common asthma triggers in pediatric patients and/or their parents who presented to the ED with asthma.

\section{METHODS}

\section{Study design}

The present prospective study was conducted in the ED at the Children's Hospital of Eastern Ontario (Ottawa, Ontario), over a one-year period from June 2009 to July 2010.

\section{Study protocol}

Children one to 17 years of age who presented to the ED with a diagnosis of asthma for at least three months were asked to participate in the study. The study pharmacist identified asthmatic patients by use of the ED manager (computer system) and/or documentation of inhaler use in the patients' chart. These patients and/or their parent or guardian were then approached by a health care professional involved in the patients' circle of care to be made aware of the study. Patients could be approached to complete the testing any time after they had been triaged, and received initial treatment or assessment of their presenting condition. Verbal consent was obtained from all study participants.

Consenting patients and/or their parent or guardian were then approached by the study pharmacist. After a brief description of the study, the patient/parent was shown a series of eight illustrations arranged in random order, and was asked to classify the illustrations as representing the following:

1. Good asthma control (able to breath and play normally);

2. Moderate or partly controlled asthma (cough, waking up at night because of asthma);
3. Bad asthma control (increasing shortness of breath, requiring increased use of rescue inhaler; or

4. An emergency situation (severe shortness of breath, trouble breathing, walking or talking).

The patient and/or parent was then asked to identify the asthma triggers depicted in a series of seven illustrations. This was to determine the patient's understanding of what each image was meant to portray (defined as guessability).

The study pharmacist then explained to the patient/parent what each of the 15 illustrations was meant to portray. Children 10 to 17 years of age, and the parents of children one to nine years of age were then asked to score (on a scale of 1 to 7 ) how well they believed the illustration represented what it was meant to portray (defined as translucency). A rating of 1 indicated there was no relationship between the illustration and its intended meaning, while a rating of 7 indicated a very strong relationship. For any illustration that received a translucency score $<6$, the child and/or parent was asked how they would better illustrate the concept.

A literacy assessment of all adult participants of children one to nine years of age was completed using the Rapid Estimate of Adult Literacy in Medicine (REALM) list of medically related words. The adolescent version, REALM-Teen, was used for all children 10 to 17 years of age $(18,20)$. These rapid screening tools (REALM and REALM-Teen) are word recognition tests that are frequently used to assess health literacy in clinical research $(20,28)$. All participants were given the appropriate list of 66 medically related words, and were asked to read the words aloud while the study pharmacist recorded correct, mispronounced and not-attempted word pronunciations. Total scores of correctly pronounced words were used to categorize the participant into one of four literacy levels judged to be equivalent to grades 0 to 12 .

\section{Ethical considerations}

The present study was approved by the Research Ethics Board of the Children's Hospital of Eastern Ontario. A protocol amendment and approval was granted by the research ethics board to incorporate and capture data regarding the frequency, type and duration of asthma education and medication counselling provided by the study pharmacist. In the present study, a significant need was identified after enrolling an initial eight patients in which more than one-third $(n=3$ [37.5\%]) of study participants required significant asthma education and counselling as deemed by the study pharmacist. Asthma education and medication counselling was provided by the study pharmacist if requested by the patient or parent, or if deemed necessary by the study pharmacist, based on the pharmacists' professional discretion and ethical obligation to provide appropriate pharmaceutical care. Education and medication counselling was tailored to the patients' and parents' specific needs. The type of asthma education and counselling provided, and the time required to provide this information, was recorded.

\section{Data analysis}

The guessability of each of the 15 illustrations was scored as correct or incorrect by each patient (or parent) enrolled in the study. To be validated, each illustration was required to be understood by at least $80 \%$ of the study participants. A translucency score $<6$ was the acceptable minimum score used to define a good relationship between the illustrations and the intended meaning.

Guessability and translucency scores were tabulated on a regular basis. Any illustration with an overall guessability score $<80 \%$ and/or a translucency median score $<6$, was reviewed by the study team and modified by the study's graphic designer. Modifications made were based on key concepts identified by the study participants. All modifications were made by the same graphic designer. Illustrations maintained consistency in figure size, weights and border to maintain a balance among the symbols as a set.

A sample size of 25 patients per group (children one to nine years of age, and children 10 to 17 years of age) was calculated using the 
sample size calculation for binomial proportions using a standard error of 0.8 , which enabled prediction of the guessability and translucency of the illustrations to within $20 \%$ of the actual scores obtained in the study. The study continued to test all of the illustrations (15) until each individual illustration (including the modified illustrations) was tested in at least 25 patients in each age group (one to nine years of age, and 10 to 17 years of age). The modified figures were reviewed by patients naive to the illustrations; the patients who previously offered suggestions for changes to the illustrations were not asked to comment. Therefore, the effectiveness of the illustrations was gauged in individuals different from those who had originally offered suggestions for modifications.

Statistical analysis was performed using SPSS version 16.0 (IBM Corporation, USA). All data were reported using descriptive statistics. Dichotomous variables are presented as percentages, normally distributed continuous variables are presented as means and SDs, and continuous variables not normally distributed are presented as medians.

\section{RESULTS}

A total of 80 patients were interviewed. Forty-two (53\%) were between one and nine years of age, while 38 (47\%) of study participants were between 10 and 17 years of age. Demographic data are summarized in Table 1. According to the REALM and REALM-Teen questionnaire, $61 \%$ of pediatric patients (between 10 and 17 years of age) and $93 \%$ of the parents of pediatric patients between one and nine years of age had at least a grade nine education.

Guessability and translucency results

The guessability and translucency results are presented in Tables 2 and 3, respectively. Table 4 summarizes all of the modifications made to the illustrations throughout the study. Seven of the original 15 illustrations $(47 \%)$ required modifications to obtain the prespecified goals of achieving a guessability score $>80 \%$ and a translucency score $\geq 6$ for each individual illustration. Four of the original eight illustrations (50\%) depicting different levels of asthma control required modification, while three of the original seven illustrations (43\%) depicting different asthma triggers required modification.

In terms of guessability, all seven of the illustrations that required modification failed to achieve a guessability score of $>80 \%$ in the children interviewed. Two of these illustrations, however, as shown in
TABLE 1

Demographic data of study participants

\begin{tabular}{lcc}
\hline & \multicolumn{2}{c}{ Child age, years } \\
\cline { 2 - 3 } & $\mathbf{1 - 9}(\mathbf{n = 4 2})$ & $\mathbf{1 0 - 1 7}(\mathbf{n = 3 8})$ \\
\hline Male sex & $27(64.7)$ & $23(60.5)$ \\
Education level & \multicolumn{2}{c}{ Parents } \\
\hline None & $0(0)$ & $0(0)$ \\
Grades 1-3 & $0(0)$ & $0(0)$ \\
Grades 4-6 & $0(0)$ & $12(31.6)$ \\
Grades 7-8 & $0(0)$ & $13(34.2)$ \\
Grade $\geq 9$ & $3(7.1)$ & $10(26.4)$ \\
College/university & $36(85.7)$ & $0(0)$ \\
Postgraduate studies & $2(4.8)$ & $0(0)$ \\
Health literacy, & & \\
grade equivalent (raw score) & REALM & REALM-Teen \\
\hline$\leq 3(0-18)$ & $0(0)$ & $0(0)$ \\
4-6 (19-44) & $0(0)$ & $3(7.9)$ \\
7-8 (45-60) & $3(7.1)$ & $11(28.9)$ \\
$\geq 9(61-66)$ & $39(92.9)$ & $23(60.5)$ \\
\hline Data presented as &
\end{tabular}

Data presented as $n$ (\%). REALM Rapid Estimate of Adult Literacy in Medicine

Table 4 ('moderate control' and 'cold'), while unclear to children were guessable by parents (of pediatric patients between one and nine years of age). Four of the seven (57\%) illustrations requiring modification failed to achieve a median translucency score of $\geq 6$ in the children and/or parents interviewed.

Asthma education and medication counselling

Asthma education and medication counselling was provided by the study pharmacist to $73 \%$ (58) of patients and/or parents enrolled in the study. Forty-three per cent of these education and counselling sessions were the result of questions and concerns voiced by the patient and/or parent, while the other $57 \%$ of education and counselling sessions were initiated by the pharmacist, based on the pharmacist's professional discretion. Table 5 details the areas of education and counselling that were provided. The average time spent counselling was $13 \mathrm{~min}$, and ranged from $5 \mathrm{~min}$ to $60 \mathrm{~min}$ per patient.

TABLE 2

Asthma control

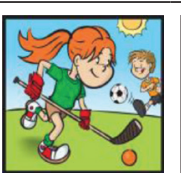

(1) Good

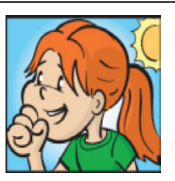

(2) Good

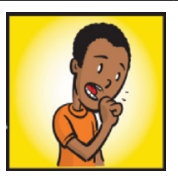

(3) Moderate

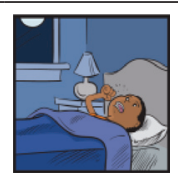

(4) Moderate

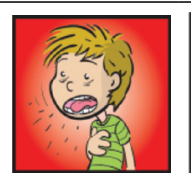

(5) Bad

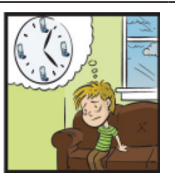

(6) Bad

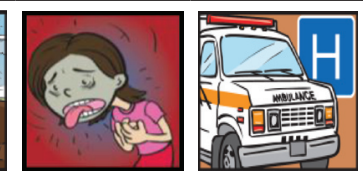

(7) Emergency (8) Emergency

\begin{tabular}{|c|c|c|c|c|c|c|c|c|}
\hline (Pictogram number) description & (1) Good & (2) Good & (3) Moderate & (4) Moderate & (5) Bad & (6) Bad & (7) Emergency (8) & ) Emergency \\
\hline & \multicolumn{8}{|c|}{ Parents (children 1-9 years of age) } \\
\hline Group, n & 42 & 39 & 42 & 39 & 28 & 28 & 42 & 42 \\
\hline \multicolumn{9}{|l|}{ Guessability } \\
\hline Correct, n (\%) & $42(100)$ & $33(84.6)$ & $40(95.2)$ & $32(82.1)$ & $27(96.4)$ & $28(100)$ & $41(97.6)$ & $41(97.6)$ \\
\hline \multicolumn{9}{|l|}{ Translucency* } \\
\hline Median (minimum-maximum) & $7(7-7)$ & $6(3-7)$ & $7(4-7)$ & $6(2-7)$ & $6(4-7)$ & $6(4-7)$ & $7(5-7)$ & $7(7-7)$ \\
\hline \multirow[t]{2}{*}{ Score $\geq 6, \mathrm{n}(\%)$} & $42(100)$ & $37(94.9)$ & $41(97.6)$ & $36(92.3)$ & $27(96.4)$ & $27(96.4)$ & $42(100)$ & $42(100)$ \\
\hline & \multicolumn{8}{|c|}{ Children $10-17$ years of age } \\
\hline Group, n & 38 & 33 & 37 & 33 & 29 & 29 & 38 & 38 \\
\hline \multicolumn{9}{|l|}{ Guessability } \\
\hline Correct, n (\%) & $38(100)$ & $27(81.8)$ & $38(100)$ & $28(84.8)$ & $28(96.6)$ & $26(89.7)$ & $38(100)$ & $38(100)$ \\
\hline \multicolumn{9}{|l|}{ Translucency* } \\
\hline Group, $\mathrm{n}^{\dagger}$ & 37 & 32 & 36 & 32 & 28 & 28 & 37 & 37 \\
\hline Median (minimum-maximum) & $7(5-7)$ & $6.5(5-7)$ & $6(3-7)$ & $6(4-7)$ & $6(5-7)$ & $6(2-7)$ & $7(6-7)$ & $7(7-7)$ \\
\hline Score $\geq 6, n(\%)$ & $36(94.7)$ & $32(97)$ & $34(89.5)$ & $31(94)$ & $28(96.6)$ & $28(93.1)$ & $37(97.4)$ & $37(97.4)$ \\
\hline
\end{tabular}

*Translucency scale: $1-7$ (1 = no relationship between illustration and intended meaning, 7 = very strong relationship); ${ }^{\dagger}$ One child did not understand the $1-7$ translucency scale; therefore, it was not completed 


\begin{tabular}{|c|c|c|c|c|c|c|c|}
\hline \multirow[t]{2}{*}{ (Pictogram number) description } & (9) Cold & (10) Smoking & (11) Pollution & (12) Mold & (13) Pets & (14) Pollen & (15) Dust mites \\
\hline & \multicolumn{7}{|c|}{ Parents (children 1-9 years of age) } \\
\hline Group, $\mathrm{n}$ & 28 & 42 & 42 & 39 & 42 & 28 & 42 \\
\hline Correct, n (\%) & $26(92.9)$ & $42(100)$ & $41(97.6)$ & $37(94.9)$ & $42(100)$ & $28(100)$ & $37(88.1)$ \\
\hline \multicolumn{8}{|l|}{ Translucency* } \\
\hline Median (minimum-maximum) & $7(5-7)$ & $7(6-7)$ & $7(5-7)$ & $7(1-7)$ & $7(3-7)$ & $7(4-7)$ & $7(3-7)$ \\
\hline \multirow[t]{2}{*}{ Score $\geq 6, \mathrm{n}(\%)$} & $28(100)$ & $42(100)$ & $42(100)$ & $35(89.7)$ & $41(97.6)$ & 27 (96.5) & $40(95.2)$ \\
\hline & \multicolumn{7}{|c|}{ Children $10-17$ years of age } \\
\hline Group, $\mathrm{n}$ & 29 & 38 & 38 & 33 & 38 & 29 & 38 \\
\hline Median (minimum-maximum) & $7(5-7)$ & $7(5-7)$ & $7(6-7)$ & $6(2-7)$ & $7(4-7)$ & $6.5(5-7)$ & $6(2-7)$ \\
\hline Score $\geq 6, \mathrm{n}(\%)$ & $28(96.6)$ & $37(97.4)$ & $37(97.4)$ & $30(84.8)$ & $36(94.8)$ & $28(96.6)$ & $28(73.7)$ \\
\hline
\end{tabular}

${ }^{*}$ Translucency scale: 1-7 (1 = no relationship between illustration and intended meaning, 7 = very strong relationship); ${ }^{\dagger}$ One child did not understand the $1-7$ translucency scale; therefore, it was not completed

\section{DISCUSSION}

While advertisers have been coupling pictures and words for decades to aid in the successful transfer of information, the use of pictorial aids in medicine, while becoming more common, is still a relatively new practice and is largely unexplored in pediatric patients. Written asthma action plans incorporating pictorial aids have been developed and used in children $(29,30)$; however, the present study was the first designed to prospectively validate the set of pictorial aids that will be incorporated into a pediatric asthma action plan in the patients (and families) who will be using the plan.

Producing pictorial aids that can be comprehended by a variety of patients with variable backgrounds (ie, ethnicity, knowledge etc) is difficult. As such, the design and evaluation of pictorial aids is a complex, multistage, iterative process (21). One of the main strategies used to ensure the understanding and comprehensibility of images developed is to identify and involve the target population in which the pictorial aids will be used in all stages of image design, evaluation and implementation $(25,31)$. In the present study, a graphic designer developed the original illustrations. The design of our original 15 illustrations was based on key findings identified by a multidisciplinary teams' evaluation of drawings obtained from pediatric patients with chronic asthma (32). Modifications were made to specific illustrations throughout the study, and were based on key concepts identified by the study participants. The process we followed to develop our initial 15 illustrations was similar to the process followed by McGrath et al (33) in the development of the Dalhousie Dyspnea Scale. Their purpose was to develop pictorial scale(s) that could be used to determine the severity of dyspnea in children. They successfully developed and validated three pictorial scales illustrating three subconstructs of dyspnea (throat constriction, chest tightness and effort) in pediatric patients between eight and 18 years of age (33). Similar to the illustrations incorporated in the Dalhousie Dyspnea Scales that encompassed the full range of the perception of breathlessness, we developed a series of illustrations that represent the full range of asthma control (from good asthma control to an emergency situation) in addition to a series of illustrations representing common asthma triggers.

Seven of our original 15 illustrations (47\%) required modifications to obtain our prespecified guessability and translucency goals, demonstrating that what we, as health care professionals, perceive to be clear and meaningful information and does not necessarily hold true for children or for the general public. Furthermore, as shown in Table 4, parents and children perceive illustrations differently. If we expect an asthma action plan to be used and used effectively, we must tailor this plan to be applicable to the patient population we are serving. Only after incorporating feedback from the pediatric patients and parents we interviewed, were we able to successfully validate a series of eight illustrations depicting four different levels of asthma control, and seven illustrations depicting common asthma triggers in pediatric asthma patients presenting to the ED with a history of chronic asthma.

An important component of a patient's understanding and comprehension of their disease state and treatment regimen that must not be overlooked is the education and medication counselling provided by health care professionals. As shown in Table 5, asthma education and medication counselling was provided by the study pharmacist to $73 \%$ of study participants. These counselling sessions were the result of either patient and/or parent requests for more information or an identified need for additional drug or disease information by the study pharmacist. This clearly demonstrates the ongoing need for improved asthma education.

\section{Study limitations}

The study pharmacist responsible for interviewing the patients, obtaining the guessability and translucency scores and seeking suggestions for illustration modification by the study participants was involved in the modification of the revised illustrations. While this may bias future testing, the study protocol was clearly established up front and followed in a stepwise process for all illustrations tested throughout the study.

A modification to the translucency scoring system that enabled us to capture both the parents' and the children's translucency scores (for children 10 to 17 years of age) was implemented after initially enrolling eight patients. This amendment was implemented because there was concern regarding the ability of children to use the 7-point rating scale (children were arbitrarily choosing numbers). Future studies may investigate using a clearer and simpler method and/or scale to assess translucency in children.

Finally, the patient population enrolled in the present study was highly literate (91\% of parents interviewed had obtained at least a college or university degree, while the average reading level of children 
TABLE 4

Modified illustrations

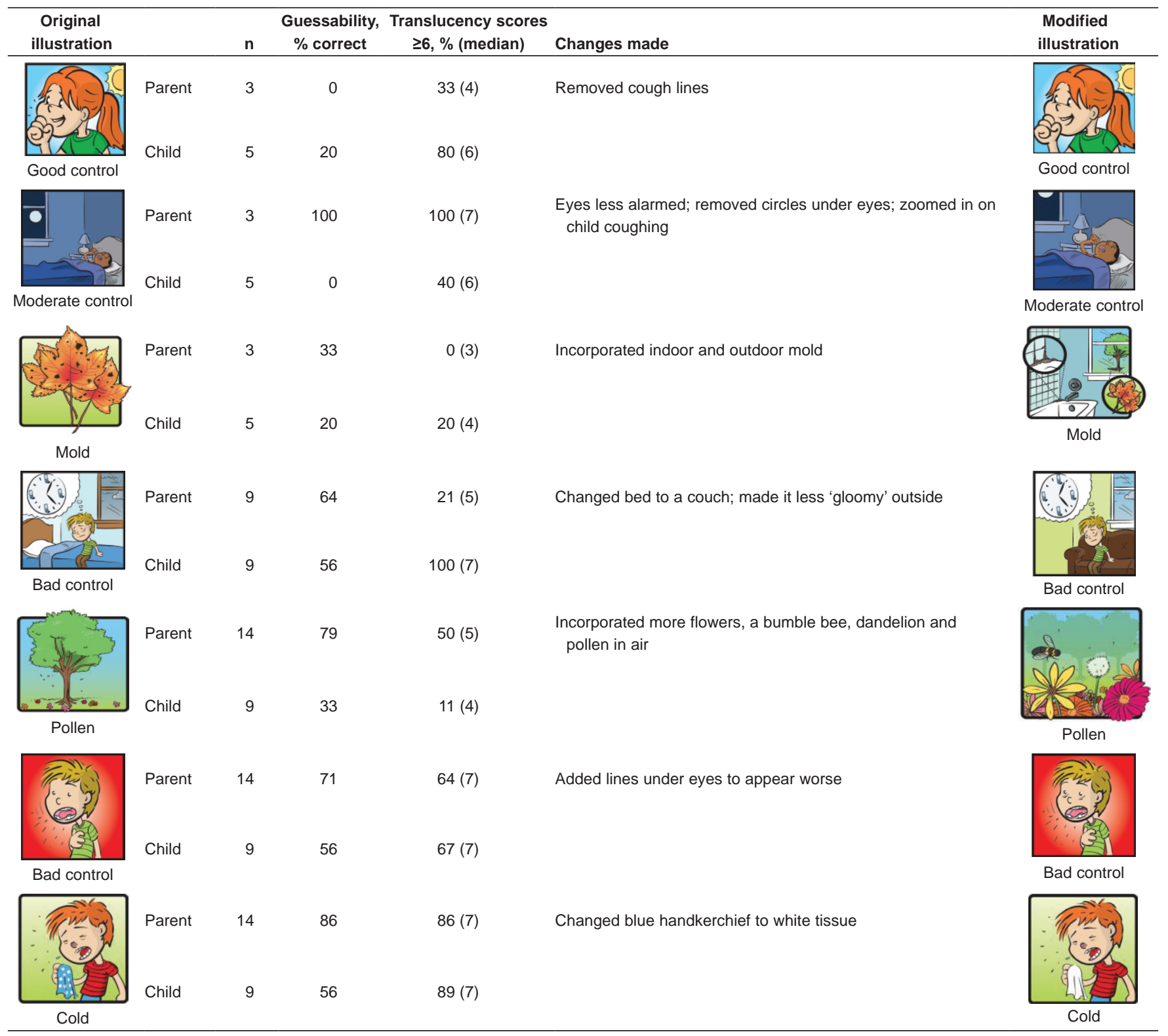

TABLE 5

\section{Asthma education and counselling}

\begin{tabular}{lcc}
\hline \multicolumn{1}{c}{$\begin{array}{c}\text { Parents } \\
\text { (of children } \\
\text { 1-9 years of age) }\end{array}$} & $\begin{array}{c}\text { Children } \\
\text { 10-17 years } \\
\text { of age }\end{array}$ \\
\hline $\begin{array}{l}\text { Asthma education/counselling provided } \\
\text { Yes }\end{array}$ & $32(76.2)$ & $26(68.4)$ \\
No & $10(23.8)$ & $12(31.6)$ \\
Requested by patient/parent & $13(31)$ & $12(31.6)$ \\
Pharmacist intervened & $18(42.9)$ & $12(31.6)$ \\
Areas of education/counselling provided & & $25(65.8)$ \\
Asthma triggers & $20(47.6)$ & $22(57.9)$ \\
Medications & $29(69)$ & $17(44.7)$ \\
Inhaler technique & $19(45.2)$ & $13(34.2)$ \\
Self-monitoring/asthma action plan & $9(21.4)$ & $13.7(5-60)$ \\
Time spent educating/counselling, min & & \\
Mean (range) & $12.3(5-40)$ &
\end{tabular}

10 to 17 years of age was equivalent or greater than a grade nine reading level). These results, therefore, cannot necessarily be generalized to patient populations with lower literacy levels.

\section{CONCLUSION}

We have successfully developed, modified and validated a set of eight illustrations representing four different levels of asthma control (good, moderate, bad and emergency) and seven illustrations representing common asthma triggers, in a total sample of 80 pediatric patients (between 10 and 17 years of age) and parents of pediatric patients (between one and nine years of age) who presented to the ED with a history of asthma.

Practice implications

These validated illustrations will be incorporated into a four-zone asthma action plan designed to better communicate health instructions and longterm asthma self-management skills to pediatric patients and/or their parents/guardians. With this asthma action plan, in conjunction with ongoing asthma education and medication counselling, we hope to improve the overall management of pediatric asthma. 
ACKNOWLEDGEMENT: The authors thank graphic designer Marc Audet from Rocket 57 (Ottawa, Ontario) for his work in designing the asthma pictograms. This project is a component of a global initiative by the International Pharmaceutical Federation (FIP) for developing illustration-based patient education tools for asthma.

FINANCIAL SUPPORT: This research was supported by a bursary from the 2008 Medbuy Endowment Fund Grant.

DISCLOSURES: None of the authors have any financial or ethical conflicts of interest regarding the contents of this article to disclose.

\section{REFERENCES}

1. Statistics Canada, CANSIM, tables 105-0501 and Catalogue no. 82-221-X. <www40.statcan.gc.ca/101/cst01/health49a-eng.htm>. (Accessed on January 11, 2012)

2. Guttmann A, Zagorski B, Austin PC, et al. Effectiveness of emergency department asthma management strategies on return visits in children: A population-based study. Pediatrics 2007;120:e1402-10.

3. Canadian Lung Association. Lung Facts 2004 update. <www.asthma.ca/corp/newsroom/pdf/asthmastats.pdf> (Accessed on June 23, 2009).

4. Global Initiative for Asthma. Global Strategy for Asthma Diagnosis and Prevention. Global Initiative for Asthma (updated 2008). <www.ginasthma.org> (Accessed on June 25, 2009).

5. Ducharme FM, Bhogal SK. The role of written action plans in childhood asthma. Curr Opin Allergy Clin Immunol 2008;8:177-88

6. Guevara JP, Wolf FM, Grum CM, Clark NM. Effects of educational interventions for self management of asthma in children and adolescents: Systematic review and meta-analysis. BMJ 2003;326:1308-9.

7. Sockrider MM, Abramson S, Brooks E, et al. Delivering tailored asthma family education in a pediatric emergency department setting: A pilot study. Pediatrics 2006;117:S135-44.

8. Zemek RL, Bhogal SK, Ducharme FM. Systematic review of randomized controlled trials examining written action plans in children: What is the plan? Arch Pediatr Adolesc Med 2008;162:157-63.

9. Albright J, de Guzman C, Acebo P, Paiva D, Faulkner M, Swanson J. Readability of patient education materials: Implications for clinical practice. Appl Nurs Res 1996;9:139-43.

10. D'Alessandro DM, Kingsley P, Johnson-West J. The readability of pediatric patient education materials on the world wide web. Arch Pediatr Adolesc Med 2001;155:807-12.

11. Forbis SG, Aligne CA. Poor readability of written asthma management plans found in national guidelines. Pediatrics 2002;109:e52.

12. Katz M, Kripalani S, Weiss B. Use of pictorial adis in medication instructions: A review of the literature. Am J Health Syst Pharm 2006;63:2391-97.

13. DeWalt DA, Dilling MH, Rosenthal MS, Pignone MP. Low parental literacy is associated with worse asthma care measures in children. Ambul Pediatr 2007;7:25-31.

14. Paasche-Orlow M, Riekert K BA, Chanmugam A, et al. Tailored education may reduce health literacy disparities in asthma self-management. Am J Respir Crit Care Med 2005;172:980-6.
15. Sanders LM, Federico S, Klass P, Abrams MA, Dreyer B Literacy and child health: A systematic review. Arch Pediatr Adolesc Med 2009;163:131-40.

16. Shone LP, Conn KM, Sanders L, Halterman JS. The role of parent health literacy among urban children with persistent asthma. Patient Educ Couns 2009;75:368-75.

17. Wittich AR, Mangan J, Grad R, Wang W, Gerald LB. Pediatric asthma: Caregiver health literacy and the clinician's perception. J Asthma 2007;44:51-5.

18. Yin HS, Forbis SG, Dreyer BP. Health literacy and pediatric health. Curr Probl Pediatr Adolesc Health Care 2007;37:258-86.

19. Houts PS, Doak CC, Doak LG, Loscalzo MJ. The role of pictures in improving health communication: A review of research on attention, comprehension, recall, and adherence. Patient Educ Couns 2006;61:173-90.

20. Davis TC, Wolf MS, Arnold CL, et al. Development and validation of the Rapid Estimate of Adolescent Literacy in Medicine (REALM-Teen): A tool to screen adolescents for below-grade reading in health care settings. Pediatrics 2006;118:e1707-14.

21. Dowse R, Ehlers M. Medicine labels incorporating pictograms: Do they influence understanding and adherence? Patient Educ Couns 2005;58:63-70.

22. Kassam R, Vaillancourt R, Collins J. Pictographic instructions for medications: Do different cultures interpret them differently? Int J Pharm Pract 2004;12:199-209.

23. Roberts NJ, Mohamed Z, Wong PS, Johnson M, Loh LC, Partridge MR. The development and comprehensibility of a pictorial asthma action plan. Patient Educ Couns 2009;74:12-8.

24. Hameen-Anttila K, Kemppainen K, Enlund H, Bush Patricia J, Marja A. Do pictograms improve children's understanding of medicine leaflet information? Patient Educ Couns 2004;55:371-8.

25. Mansoor LE, Dowse R. Effect of pictograms on readability of patient information materials. Ann Pharmacother 2003;37:1003-9.

26. Yin HS, Dreyer BP, van Schaick L, Foltin GL, Dinglas C, Mendelsohn AL. Randomized controlled trial of a pictogram-based intervention to reduce liquid medication dosing errors and improve adherence among caregivers of young children. Arch Pediatr Adolesc Med 2008;162:814-22.

27. International Pharmacy Federation (FIP). FIP Statement of Principle: The pharmacist's responsibility and role in teaching children and adolescents about medicines. <www.fip.nl/resources/ adolscents-English.htm> (Accessed on June 25, 2009).

28. Davis TC, Long SW, Jackson RH, et al. Rapid estimate of adult literacy in medicine: A shortened screening instrument. Fam Med 1993;25:391-5.

29. Calgary Health Region. iCan control asthma now. April 2009. $<$ www.calgaryhealthregion.ca/ican> (Accessed on June 25, 2009).

30. Ducharme FM, Noya F, McGillivray D, et al. Two for one: A self-management plan coupled with a prescription sheet for children with asthma. Can Respir J 2008;15:347-54.

31. Roberts NJ, Ghiassi R, Partridge MR. Health literacy in COPD. Int J Chron Obstruct Pulmon Dis 2008;3:499-507.

32. Pascuet E, Vaillancourt R, Collins M A, et al. Visual thematic analysis of children's illustrations to improve receptiveness to pictorial asthma action plans. J Pharm Pract Res 2010;40:92-6.

33. McGrath PJ, Pianosi PT, Unruh AM, Buckley CP. Dalhousie dyspnea scales: Construct and content validity of pictorial scales for measuring dyspnea. BMC Pediatr 2005;5:33. 


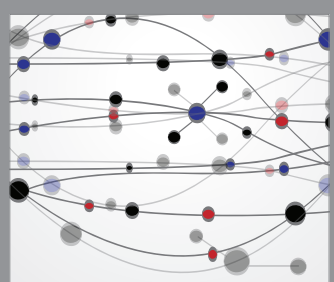

The Scientific World Journal
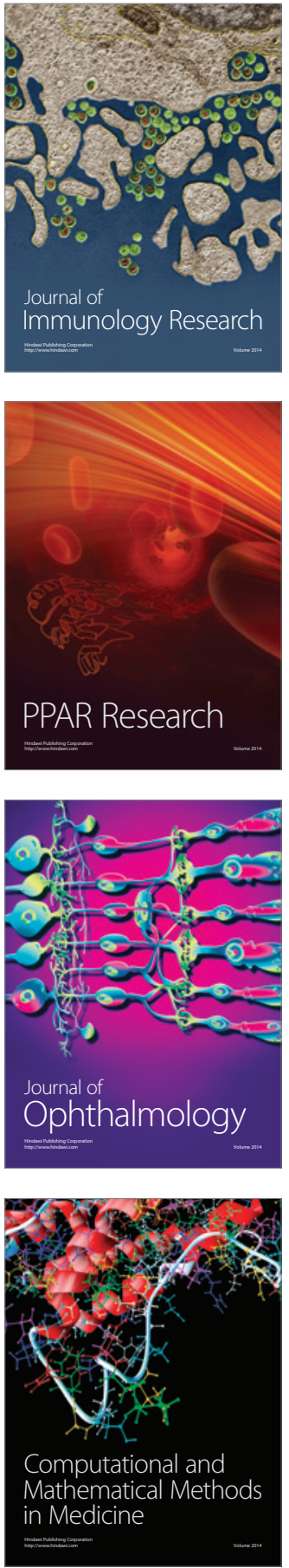

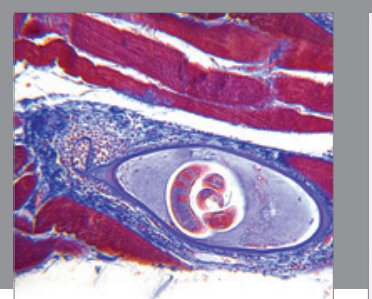

Gastroenterology Research and Practice

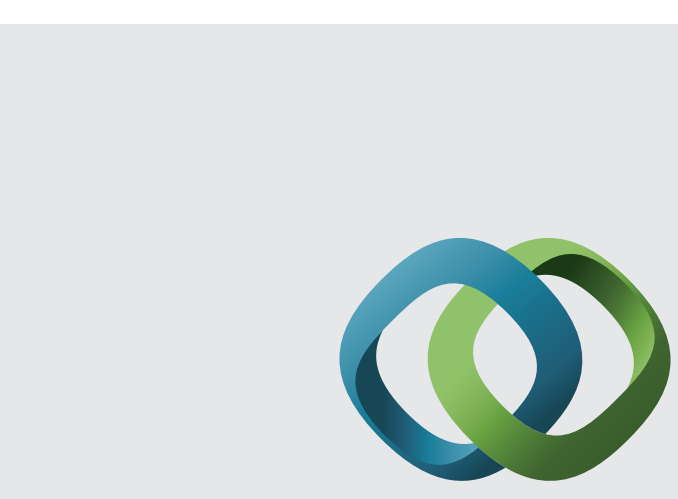

\section{Hindawi}

Submit your manuscripts at

http://www.hindawi.com
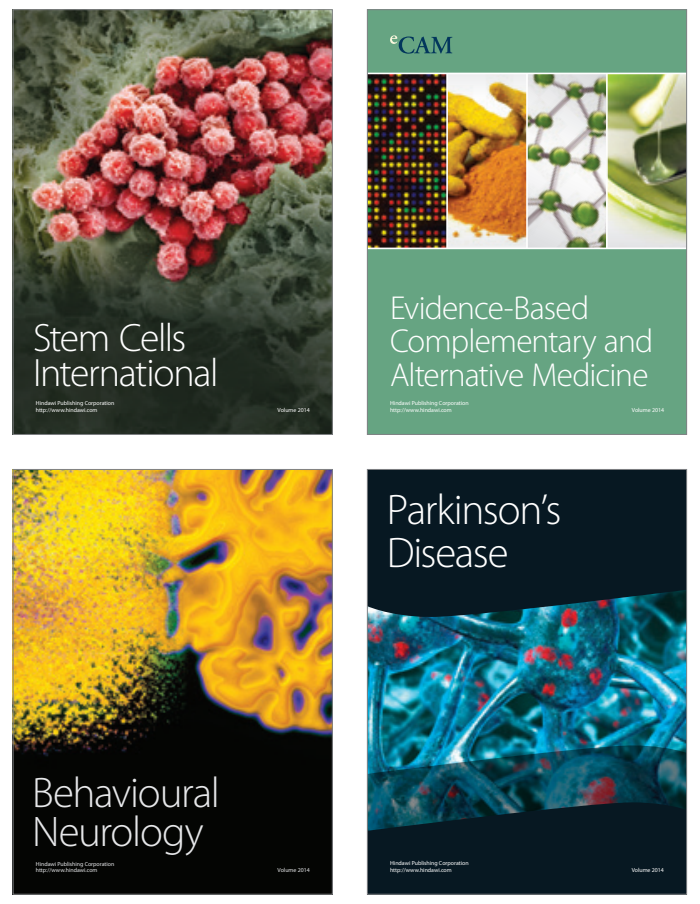
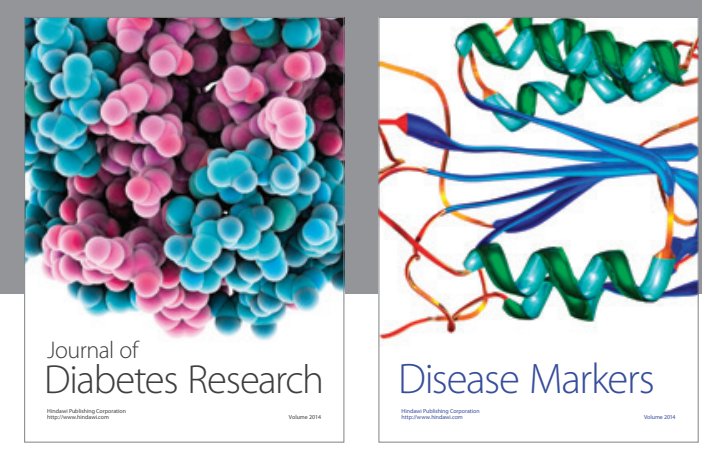

Disease Markers
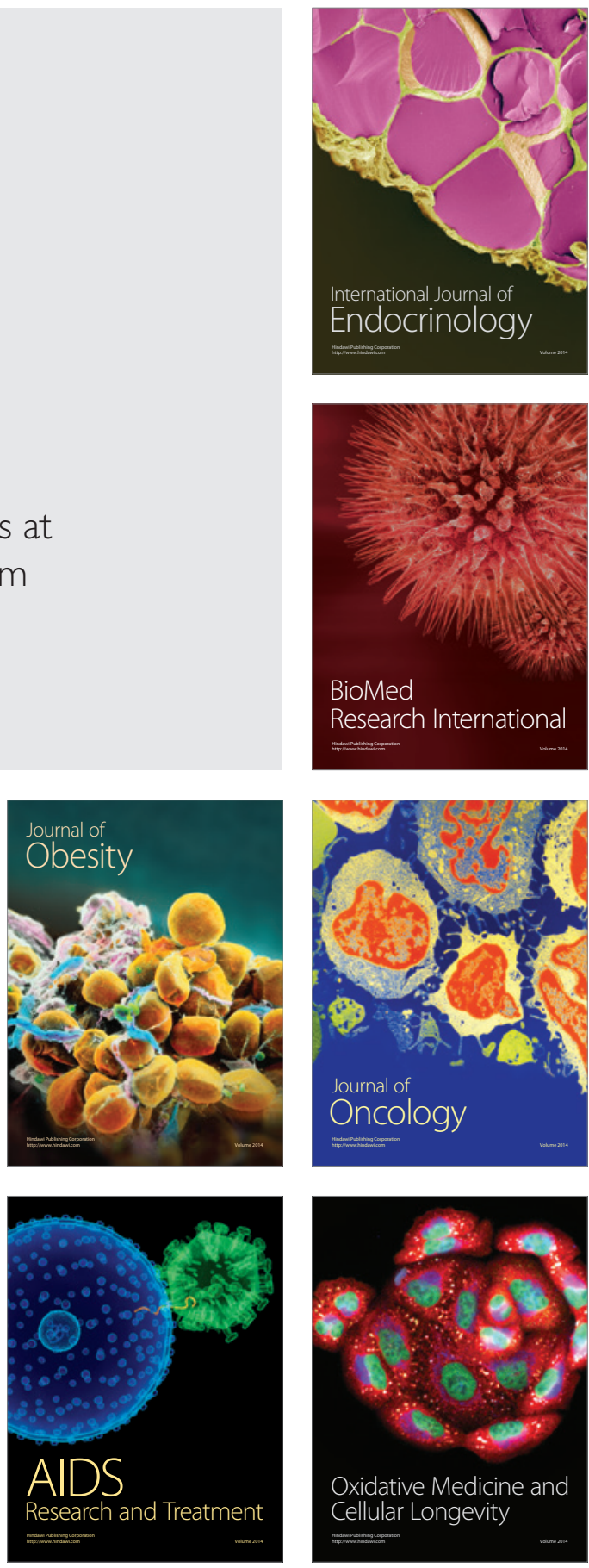